\title{
Carrier detection and early diagnosis of Wilson's disease by restriction fragment length polymorphism analysis
}

\author{
ANNALENA FIGUS, ${ }^{*}$ ROSANNA LAMPIS $\dagger$, MARCELLA DEVOTO $\ddagger$, \\ MARIA SERAFINA RISTALDI $\ddagger$, ANGELO IDEO $\dagger$, \\ STEFANO DE VIRGILIS $\dagger$, ANNA MARIA NURCHI§, \\ ADRIANO CORRIAS $\$$, ROBERTO CORDA, MARIA ELIANA LAI*, \\ ANDREINA TOCCO\|, ANGELO DEPLANOף, ANTONELLO SOLINAS \\ LUCIA ZANCAN**, WEN-HWA LEE††, ANTONIO CAO†, \\ MARIO PIRASTU $\ddagger$, AND ANGELO BALESTRIERI*
}

From *Istituto di Medicina Interna, Clinica Medica I, †Istituto di Clinica e Biologia dell'età Evolutiva, and \$Istituto di Clinica Pediatrica, Università degli Studi di Cagliari; $\ddagger$ Genetica Molecolare, Istituto Giannina Gaslini, Genova; |Istituto di Anatomia Patologica, Servizio di Immunopatologia, and \Clinica Medica Generale e Terapia Medica, Università degli Studi di Sassari; ${ }^{* *}$ Dipartimento di Pediatria, Università degli Studi di Padova; ††School of Medicine, Department of Pathology, La Jolla, California; and $¥ \ddagger$ Istituto di Ricerca sulle Talassemie e Anemie Mediterranee, CNR, Cagliari, Sardinia, Italy.

SUMMARY Wilson's disease, a rare autosomal recessive disorder, has been recently mapped to the long arm of chromosome 13 (q14.1). In this study, we carried out linkage analysis betweens three chromosome 13 DNA markers, D13S1, D13S10, D13S2, the locus for the red cell enzymeo esterase D $(E S D)$, and the Wilson's disease locus (WND) in 17 Wilson's disease families of Italian descent, mostly from Sardinia. We confirmed a tight linkage $[\hat{\theta}=0.00, Z(\hat{\theta})=4 \cdot 07 \mathbb{R}$ between the $W N D$ and $E S D$ loci, and provided suggestive evidence for linkage $[\hat{\theta}=0 \cdot 00, \overrightarrow{0}$ $\mathrm{Z}(\hat{\theta})=1 \cdot 85$ ] of the $W N D$ locus with $D 13 S 10$. Multipoint linkage analysis indicated the following order: centromere-D13S1-D13S10-WND-ESD-D13S2. RFLP analysis at these two loci in out families allowed us either to define the carrier status $(50 \%)$ or to exclude the homozygous state $(25 \%)$ in the great majority of unaffected sibs.

Wilson's disease, or hepatolenticular degeneration, is a rare, autosomal recessive disorder characterised by impaired biliary excretion and defective incorporation of copper into ceruloplasmin. This results in hepatic and extra-hepatic copper accumulation, low plasma concentration, and increased urinary excretion. ${ }^{1}$ Clinical presentation occurs in the first or second decade of life and is characterised either by liver disease or extrapyramidal syndrome. The variability of the clinical picture and age at presentation suggests genetic heterogeneity. ${ }^{2}$ The molecular basis of the disease is not known. Chelation therapy with penicillamine is highly effective, especially when initiated before irreversible organ damage has occurred.

Preclinical diagnosis, based on low ceruloplasmin

Received for publication 18 July 1988.

Accepted for publication 18 August 1988. levels and increased urinary copper excretion, is not completely reliable and should be confirmed by invasive methods such as liver biopsy. Carrief detection, by evaluation of ceruloplasmin levels and incorporation of ${ }^{64} \mathrm{Cu}$ into ceruloplasmin, does no? give a definite result and prenatal testing is not available. Progress in gene mapping of Wilson's disease should improve the diagnostic capabilities 0 A tight linkage between the WND and ESD loci on chromosome 13 has recently been detected. ${ }^{3-6}$ Further studies confirmed this linkage and alseb detected a tight linkage between $W N D$ and the polymorphic region $D 13 S 10$ which is detected by the single copy probe $7 \mathrm{D} 2 .^{6}$

The incidence of Wilson's disease in the Sardinian population is around 1 to $3 / 10^{4}$ livebirths, ${ }^{7}$ an ordeई of magnitude higher than in other Caucasian and non-Caucasian populations $\left(1 / 10^{5}\right) .^{1}$

In this study, we carried out linkage analysiş 
between the WND locus and several chromosome 13 polymorphic loci in 17 Italian families, mostly from Sardinia. Our results confirmed linkage between the $W N D$ locus and the ESD and D13S10 loci and showed the feasibility of early diagnosis and carrier detection by DNA analysis.

\section{Patients and methods}

\section{PATIENTS}

This study included 17 Italian families with Wilson's disease, 14 from Sardinia and three from the mainland. Nine of these families had multiple cases (fig 1). Out of 26 patients investigated, 19 were younger and seven older than 14 years. In the group of young patients, 16 had chronic liver disease and three were asymptomatic. In the group of older patients, two had the extrapyramidal syndrome, two had chronic liver disease, and three were asymptomatic.
Diagnosis was based on reduced serum ceruloplasmin and copper levels, high urinary copper excretion, and copper accumulation in the liver, evaluated by biopsy. The pertinent laboratory data on the 26 patients evaluated are presented in table 1 .

Serum ceruloplasmin levels, investigated in 34 parents, were normal in 31 and reduced in three.

DNA ANALYSIS

Leucocyte DNA extraction and restriction endonuclease analysis were carried out as previously described. $^{8}$

TABLE 1 Pertinent laboratory data of 26 Wilson's disease patients.

\begin{tabular}{lc}
\hline Serum ceruloplasmin $(\mathrm{mg} / \mathrm{d} \mathrm{l})$ & $5[3 \cdot 6](20-65)$ \\
Serum copper $(\mu \mathrm{g} / \mathrm{dl})$ & $35 \cdot 11[18 \cdot 5](65-165)$ \\
Copper excretion $(\mu \mathrm{g} / 24 \mathrm{~h})$ & $244 \cdot 89[191 \cdot 95](30-50)$ \\
Liver copper $(\mu \mathrm{g} / \mathrm{g}$ dry weight) & $1222[385 \cdot 8](20-50)$ \\
\hline
\end{tabular}

Numbers indicate mean [1 SD] followed by the range of normal values.
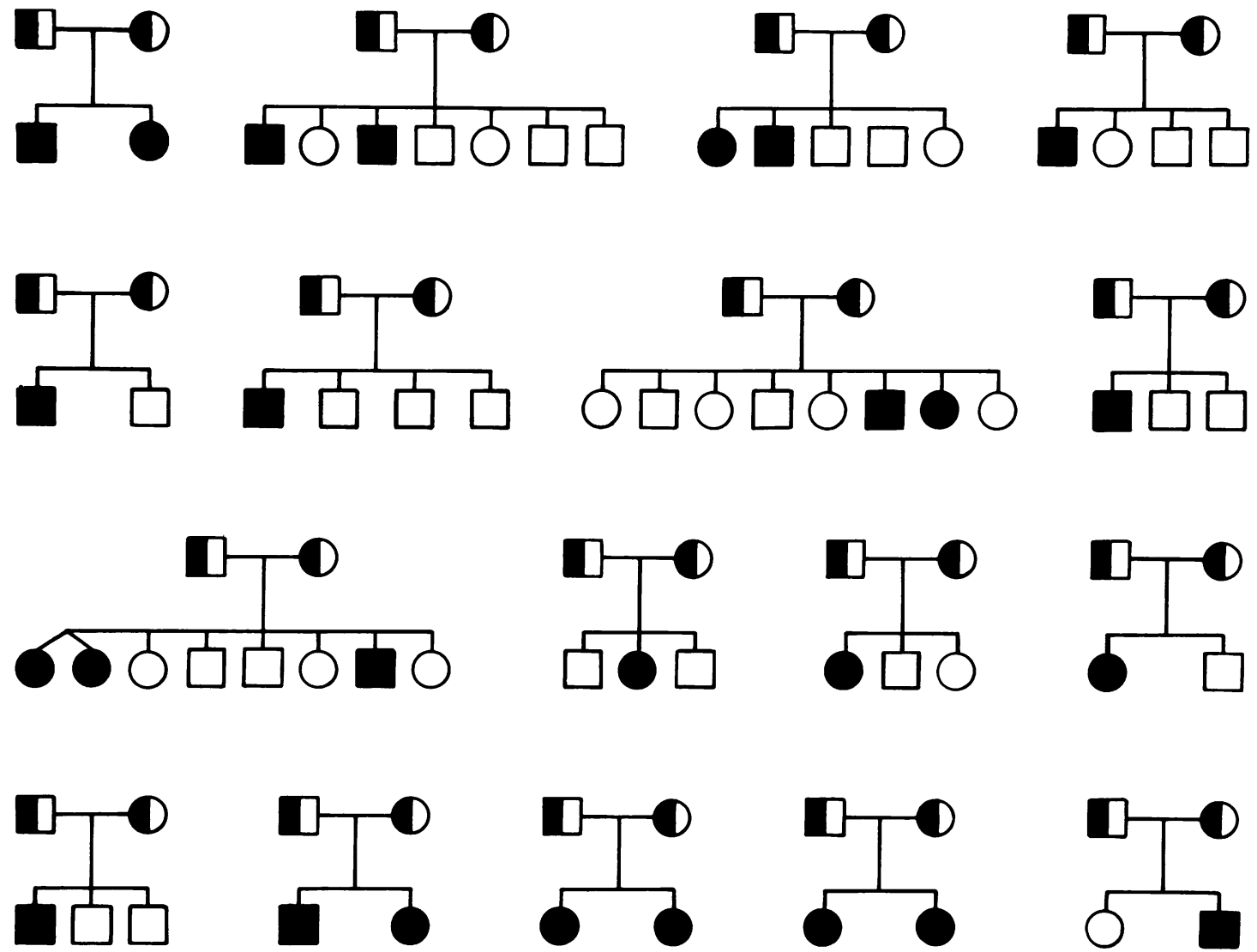

FIG 1 Pedigrees of the 17 Wilson's disease families investigated. 
Three anonymous probes, p7F12, p7D2, and p9D11, which detect RFLPs at the chromosome 13 loci $D 13 S 1, D 13 S 10$, and $D 13 S 2$ respectively, were used to hybridise Southern blots of DNA samples from members of the Wilson's disease families. In addition, an ESD cDNA probe was used to detect RFLPs at the ESD locus. The ESD isoenzymes were also determined according to Hopkinson et al. ${ }^{9}$

LINKAGE ANALYSIS

Pairwise linkage analysis between the WND locus and each of the chromosome 13 polymorphic loci in 17 informative families was performed by the lod scores method, using the MLINK program from the linkage package,${ }^{10}$ assuming a recessive model with complete penetrance and a population frequency of the WND gene of $0.002 .^{7}$ Genotypes from different polymorphisms detected by single copy probes were combined into chromosomal haplotypes. Separate lod scores for sex and one lod unit confidence intervals for the estimated recombination fractions were calculated as recommended at HGM8. ${ }^{11}$

Multipoint linkage analysis to determine the most likely order of the four marker loci and the relative position of the Wilson's disease locus among the marker loci was performed using the ILINK and LINKMAP programs from the LINKAGE package.

TABLE 2 RFLPs at four loci on chromosome 13 in 17 Italian families.

\begin{tabular}{llll}
\hline Locus & $\begin{array}{l}\text { Restriction } \\
\text { enzyme }\end{array}$ & $\begin{array}{l}\text { No of } \\
\text { subjects }\end{array}$ & $\begin{array}{l}\text { Heterozygosity } \\
(\%)\end{array}$ \\
\hline D13S1 & MspI, TaqI, BclI & 34 & $58 \cdot 8$ \\
D13S10 & TaqI, DraI & 26 & $42 \cdot 3$ \\
ESD* & ApaI & 34 & $67 \cdot 5$ \\
D13S2 & MspI, TaqI & 32 & $62 \cdot 5$ \\
\hline
\end{tabular}

*ESD isoenzymes were also investigated.

\section{Results}

RFLP ANALYSIS

We studied the heterozygosity of the parents of $\frac{\bar{c}}{\mathrm{~s}}$ patients with Wilson's disease at four chromosome13 polymorphic loci, $D 13 S 1, D 13 S 10, D 13 S 2$, and $E S D$, by RFLP analysis (table 2). More than onew RFLP was analysed for each locus. In addition, ESDserum isoenzyme polymorphism was also investigated. The highest percentage $(67.5 \%)$ of hetero- $\vec{\omega}$ zygosity was detected at the ESD locus and the? lowest $(42 \cdot 3 \%)$ at the D13S10 locus.

\section{LINKAGE ANALYSIS}

Lod scores $[\mathrm{Z}(\hat{\theta})]$ at various recombination fractions$(\hat{\theta})$ between $W N D$ and the four marker loci are reported in table 3 . Significant linkage $[Z(\hat{\theta})=4.07 \mathrm{P}$ at an estimated recombination frequency $\hat{\theta}=0.00$ was found for $E S D$, and suggestive evidence waso found for $D 13 S 10[\mathrm{Z}(\hat{\theta})=1.85, \hat{\theta}=0.00]$. Separate analysis for sex did not show any significant differences in recombination between males and females.

Multipoint linkage analysis of the four markers $\vec{\infty}$ performed to establish the most likely relative ${ }^{\Theta}$ position of the four loci on the long arm of chromosome 13, indicated that the most likely order is: centromere-D13S1-D13S10-ESD-D13S2. Sinceour data on the recombination frequencies amongo marker loci, based on a small number of families $\mathbb{D}$ were subject to large sampling errors, we used the published genetic map ${ }^{612}$ and the corresponding estimates of the recombination frequencies between each pair of loci for the purpose of establishing the relative position of the WND locus. Results of four overlapping four point analyses performed, excluding one marker at a time, indicated that the WND locuso is likely to be located distal to D13S10, but it mighe be either proximal or distal to ESD. The two most favoured orders are D13S1-D13S10-WND-ESD-そ

TABLE 3 Linkage analysis between WND and four marker loci on chromosome 13.

\begin{tabular}{|c|c|c|c|c|c|c|c|c|c|c|c|c|}
\hline \multirow[b]{2}{*}{ Locl } & \multirow[b]{2}{*}{ Loc2 } & \multirow[b]{2}{*}{ Sex } & \multirow[b]{2}{*}{$Z(\hat{\theta})$} & \multirow[b]{2}{*}{$\hat{\theta}$} & \multirow[b]{2}{*}{ CI } & \multicolumn{7}{|c|}{ Recombination fraction } \\
\hline & & & & & & 0.001 & 0.01 & 0.05 & $0 \cdot 1$ & $0 \cdot 2$ & $0 \cdot 3$ & 4 \\
\hline \multirow[t]{3}{*}{$W N D$} & $E S D$ & & $4 \cdot 7$ & 0.00 & $0.00-0.084$ & $4 \cdot 06$ & 3.93 & $3 \cdot 37$ & $2 \cdot 72$ & 1.59 & 0.74 & $0 \cdot 19$ \\
\hline & & $\mathbf{M}$ & & & & $1 \cdot 19$ & $1 \cdot 16$ & 1.01 & 0.84 & 0.52 & 0.25 & 0.07 \\
\hline & & $\mathbf{F}$ & & & & $2 \cdot 87$ & $2 \cdot 80$ & $2 \cdot 51$ & $2 \cdot 11$ & $1 \cdot 32$ & 0.62 & $0 \cdot 19$ \\
\hline \multirow[t]{3}{*}{$W N D$} & D13S1 & & 2.35 & 0.049 & $0.003-0.284$ & 1.04 & 1.98 & $2 \cdot 35$ & $2 \cdot 18$ & 1.48 & 0.75 & 0.20 \\
\hline & & $\mathbf{M}$ & & & & -0.72 & $0 \cdot 17$ & 0.68 & 0.76 & 0.62 & 0.34 & $0 \cdot 10$ \\
\hline & & $\mathbf{F}$ & & & & 1.89 & 1.85 & 1.67 & 1.45 & 0.96 & 0.52 & $0 \cdot 14$ \\
\hline \multirow[t]{3}{*}{$W N D$} & D13S10 & & 1.85 & 0.00 & $0-0.224$ & 1.85 & 1.81 & 1.63 & 1.41 & 0.96 & 0.52 & $0 \cdot 15$ \\
\hline & & $\mathbf{M}$ & & & & 0.13 & 0.12 & $0 \cdot 11$ & 0.09 & 0.05 & 0.02 & 0.01 \\
\hline & & $\mathbf{F}$ & & & & 1.72 & 1.68 & 1.53 & $1 \cdot 32$ & 0.90 & 0.46 & $0 \cdot 15$ \\
\hline \multirow[t]{3}{*}{$W N D$} & $D 13 S 2$ & & 1.46 & 0.09 & $0.002-0.299$ & -1.61 & 0.31 & $1 \cdot 33$ & 1.45 & $1 \cdot 10$ & 0.58 & $0 \cdot 16$ \\
\hline & & $\mathbf{M}$ & & & & 0.98 & 0.97 & 0.90 & 0.78 & 0.55 & 0.25 & 0.06 \\
\hline & & $\mathbf{F}$ & & & & $-3 \cdot 01$ & $-1 \cdot 38$ & -0.07 & 0.39 & 0.50 & $0 \cdot 30$ & $0 \cdot 11$ \\
\hline
\end{tabular}


D13S2 and D13S1-D13S10-ESD-WND-D13S2, with a relative likelihood of the first order over the second of approximately $4: 1$, at a recombination frequency of 0.07 between $W N D$ and $D 13 S 10$ and of 0.03 between WND and ESD.

CARRIER DETECTION OF WILSON'S DISEASE BY DNA ANALYSIS

All members, affected and unaffected, of the 17 Wilson's disease families were studied at the four polymorphic loci. Because of the high recombination between $D 13 S 1$ and $D 13 S 2$ and the $W N D$ locus $(\hat{\theta}=0.049$ and 0.09 respectively, table 3$)$ only $E S D$ and $D 13 S 10$, which showed the lowest recombination fraction with $W N D$ in our study, were used for carrier detection.

The RFLPs at these polymorphic loci were combined to obtain a chromosomal haplotype. Haplotype analysis may avoid misdiagnosis resulting from recombination between $W N D$ and one of the other two loci, an example of which is illustrated in fig 2 .

The linkage phase was established in both parents in three families (completely informative families), in one parent only in 11 (partially informative families), and in neither in three (uninformative families) (table 4).

In eight families with multiple cases, the affected sibs shared identical chromosome 13 haplotypes which were never detected in unaffected sibs.
TABLE 4 Informativeness of the Wilson's disease families at the ESD and D13S10 polymorphic loci.

\begin{tabular}{lll}
\hline & Families (17) & \\
\cline { 2 - 3 } & $\begin{array}{ll}\text { With } \\
1 \text { case (9) }\end{array}$ & $\begin{array}{l}\text { With } \\
\text { cases (8) }\end{array}$ \\
\hline One parent informative & 4 & 7 \\
Both parents informative & 2 & 1 \\
None & 3 & - \\
\hline
\end{tabular}

TABLE 5 Carrier detection by RFLP analysis in Wilson's disease families.

\begin{tabular}{lc}
\hline No of families & 17 \\
No of possible carriers investigated & 36 \\
Carrier status excluded & $2 / 36$ \\
Carrier status identified & $16 / 36$ \\
Undefined & $18 / 36$
\end{tabular}

By haplotype analysis, we investigated 36 possible carriers in the 17 Wilson's disease families. We were able to identify 16 carriers and to exclude the carrier status in two. Carrier detection was not possible in the remaining 18 . However, in 11 of them haplotype analysis allowed the exclusion of the homozygous state (table 5).

\section{Discussion}

In this study, which included a large number of

FIG 2 Pedigree of a Wilson's disease family with two affected members. The different bars indicate the chromosomal haplotype obtained analysing four chromosome 13 loci. The different alleles at each locus investigated are indicated with numbers only in the parents and in the member indicated by the arrow, where a double recombination occurred between ESD and D13S10-D13S1 in the proximal region and D13S2 in the distal region. 
families with Wilson's disease from a single population, we confirmed a tight linkage $(\hat{\theta}=0 \cdot 00)$ with a lod score of 4.07 between the gene for Wilson's disease and the $E S D$ locus. This study also provides suggestive evidence for linkage $[\hat{\theta}=0 \cdot 00, Z(\hat{\theta})=1 \cdot 85]$ between the $W N D$ and the D13S10 loci. Haplotype sharing in affected sib pairs in multicase families further supports the linkage of $W N D$ to $E S D$ and D13S10.

Multipoint linkage analysis between several chromosome 13 markers and the WND locus indicates that the most likely order is as follows: centromere-D13S1-D13S10-WND-ESD-D13S2. This order corresponds to the less favoured one proposed by Bowcock et at (D13S10-WND-ESD-D13S2 or D13S10-ESD-WND-D13S2) on the basis of their analysis of five families with Wilson's disease from different populations.

The extreme variation in the clinical picture and the marked difference in age at presentation suggest that Wilson's disease may be heterogeneous at the molecular level. This heterogeneity could be allelic or non-allelic. Non-allelic heterogeneity should be excluded before applying, at the clinical level, polymorphism analysis based on linkage between markers and the disease locus detected in some families. All the 17 families investigated in this study were independently ascertained and in all of them the WND locus was linked to chromosome 13 markers. From these data it seems reasonable to assume that, at least in the Sardinian population, Wilson's disease is largely caused by mutation(s) at the WND locus located on chromosome 13.

The p7D2 and ESD gene probes are informative in approximately $35.3 \%$ and $64.7 \%$ of matings and, given the linkage to the WND locus, would provide the tools for preclinical diagnosis, heterozygote detection, and prenatal diagnosis.

RFLP analysis at these two loci in our families allowed us either to define the genotype $(50 \%)$ or to exclude the homozygous state $(25 \%)$ in the large majority $(75 \%)$ of unaffected sibs. However, recombination between $W N D$ and either $E S D$ or D13S10 may occur and result in misdiagnosis. Although in our samples the maximum likelihood estimate of the recombination distance between $W N D$ and the two linked RFLP markers is 0.00 , the $90 \%$ confidence interval for the recombination distance should be used for the conservative estimate of the probability of an at risk fetus being affected with Wilson's disease. On the assumption that $E S D$ and $D 13 S 10$ flank $W N D$, by using both polymorphic loci considered as haplotypes in informative families the risk of a sib sharing the same haplotypes as the proband would be adjusted from $25 \%$ to $98.2 \%$, while the probability of being heterozygous woulch be $1.7 \%$. If the order of loci is D13S10-ESD-WND false negative and false positive diagnoses would be in the order of $11.3 \%$ and $5.8 \%$ respectively.

Prenatal diagnosis of Wilson's disease will be $\overrightarrow{-}$ greatly facilitated when new probes linked to the$W N D$ locus are available and the order of the probesw along chromosome 13 defined.

We would like to thank $R$ White and P O'Connelp for the gift of probes p7F12, p7D2, and p9D11. Thiso work was supported in part by grants from the Assessorato Igiene e Sanità Regione Autonomaoo della Sardegna.

\section{References}

${ }^{1}$ Danks DM. Hereditary disorders of copper metabolism inf Wilson's disease and Menke's disease. In: Stanbury JB Wyngaarden JB, Fredrickson DS, Goldstein JL, Brown MS רٕ eds. The metabolic basis of inherited disease. New York: McGraw-Hill, 1983:1251-61.

2 Cox DW, Fraser FC, Sass-Kortsak A. A genetic study opo Wilson's disease: evidence for heterogeneity. Am J Hum Genet 1972;24:646-66.

${ }^{3}$ Frydman F, Bonné-Tamir B, Farrer LA, et al. Assignment of the gene for Wilson disease to chromosome 13: linkage to esterase D locus. Proc Natl Acad Sci USA 1985;82:1819-21.

${ }^{4}$ Bonné-Tamir B, Farrer LA, Frydman M, Kanaaneh H. Evidenceڤ̆ for linkage between Wilson's disease and esterase $D$ in three kindreds: detection of linkage for an autosomal recessive disorder by the family study method. Genet Epidemiol 1986;3음 201-9.

5 Yuzbasyan-Gurkan V, Brewer GJ, Boerwinkle E, Venta PJ Linkage of the Wilson disease gene to chromosome 13 in North American pedigrees. Am J Hum Genet 1988;42:825-9.

6 Bowcock AM, Farrer LA, Cavalli-Sforza LL, et al. Mapping the Wilson disease locus to a cluster of linked polymorphic markerso on chromosome 13. Am J Hum Genet 1987;41:27-35.

7 Giagheddu A, Demelia L, Puggioni G, et al. Epidemiologic study of hepatolenticular degeneration (Wilson's disease) in Sardinia (1902-1983). Acta Neurol Scand 1985;72:43-55.

${ }^{8}$ Goossens M, Kan YW. DNA analysis in the diagnosis of hemoglobin disorders. Methods Enzymol 1981;76:805-17.

9 Hopkinson DA, Mestriner MA, Cortner J, Harris H. Esterase D: a new human polymorphism. Ann Hum Genet 1973;37 119-37.

10 Lathrop GM, Lalouel JM. Easy calculation of lod-scores andu genetic risks on small computers. Am J Hum Genet 1984;36. 460-5.

11 Buys CHCM, Scheffer H, Pearson PPL, Aanstoot GH, Goor N Nienhaus AJ. Human gene mapping 8. Cytogenet Cell Genefu 1985;40:597.

12 Leppert M, Cavenee W, Callahan $P$, et al. A primary geneti६ map of chromosome 13q. Am J Hum Genet 1986;39:425-37.

Correspondence to Dr Annalena Figus, Clo Ospedale $\stackrel{0}{+}$ Regionale per le Microcitemie, USL21, Via Jennero s/n, 09100 Cagliari, Sardinia, Italy. 